www.nature.com/pj

\title{
Depth-dependent inhomogeneous characteristics in supported glassy polystyrene films revealed by ultra-low X-ray reflectivity measurements
}

\author{
Chunming Yang ${ }^{1}$, Kohei Ishimoto ${ }^{2}$, Syunsui Matsuura ${ }^{2}$, Naoki Koyasu ${ }^{2}$ and Isao Takahashi ${ }^{2}$
}

This study reports X-ray reflectivity measurements of the glass transition of polystyrene thin films supported on Si substrates and heated at low heating rates that ranged from 0.14 to $0.01{ }^{\circ} \mathrm{C} \mathrm{min}^{-1}$. At a heating rate of $0.14{ }^{\circ} \mathrm{C} \mathrm{min}-1$, the glass transition temperature $T_{\mathrm{g}}$ was independent of the film thickness down to a thickness of $6 \mathrm{~nm}$. However, at a heating rate of $0.04{ }^{\circ} \mathrm{C} \mathrm{min}-1$, the value of $T_{\mathrm{g}}$ decreased with decreased thickness. The reduction in $T_{\mathrm{g}}$ was most significant at the ultra-low heating rate of $0.01{ }^{\circ} \mathrm{C} \mathrm{min}^{-1}$. Furthermore, with decreased film thickness, the linear thermal expansivity in the glassy state $\alpha_{\text {glass }}$ slightly decreased at a heating rate of $0.14{ }^{\circ} \mathrm{C} \mathrm{min}-1$, whereas $\alpha_{\text {glass }}$ exhibited a significant increase at the ultra-low heating rate of $0.01{ }^{\circ} \mathrm{C} \mathrm{min}^{-1}$. Reconstructed depth profiles of thermal expansivity, which were obtained by fitting the $\alpha_{\text {glass }}$ values using an integral model, indicated a decrease in the thickness of the interfacial dead layer with a decrease in the heating rate, whereas the volume fraction of the free surface region increased under this condition. The observed reduction in $T_{\mathrm{g}}$ can be attributed to surface and interface effects perturbing the glass transition dynamics of the thin films under slower probing conditions.

Polymer Journal (2014) 46, 873-879; doi:10.1038/pj.2014.80; published online 10 September 2014

\section{INTRODUCTION}

In polymer thin films, the properties in regions near interfaces differ from the bulk properties. To date, several studies have reported the presence of a distinct region near the free surface that is characterized by reduced $T_{\mathrm{g}}$ and enhanced mobility. ${ }^{1-5}$ These differences are often attributed to the special circumstances of polymer thin films that result in lowered activation barriers for molecular rearrangements. However, the region near the substrate interface is expected to have an increased $T_{\mathrm{g}}$ with lowered mobility because the molecular chains are pinned onto the substrate via interactions between the molecules and the substrate. ${ }^{6-10}$ Although the glass transition behavior of polymer thin films appears to be understood, there is no indication that the study of this issue has ceased over the past two decades.

As mentioned earlier, several studies have reported reductions in $T_{\mathrm{g}}$ and enhancements in the surface mobility of ultrathin supported films, ${ }^{11,12}$ whereas few studies claim thickness independence of $T_{\mathrm{g}}$ in glassy polymer thin films. ${ }^{13-18}$ In addition, few studies have reported that the $T_{\mathrm{g}}$ of polystyrene (PS) films decreases with decreasing thickness, whereas the linear thermal expansivity in the glassy state $\alpha_{\text {glass }}$ has been reported to increase under such conditions. ${ }^{1,19,20}$ This phenomena can be explained by assuming that the increase in $\alpha_{\text {glass }}$ is related to the enhanced mobility in the region near the free surface. However, a few other experimental studies ${ }^{21-24}$ have indicated that $\alpha_{\text {glass }}$ is either independent of the film thickness or exhibits a decreasing trend with decreasing thickness, which is accompanied by a reduction in $T_{\mathrm{g}}$. A significant decrease in $T_{\mathrm{g}}$ has been observed in thin, freestanding PS films, in which $\alpha_{\text {glass }}$ is reportedly independent of the film thickness ${ }^{4}$ or tends to decrease with decreasing thickness. ${ }^{25}$

Furthermore, atomic force microscopy analysis ${ }^{26}$ of the region near the free surface with gold nanospheres embedded in the PS surface has indicated that the temperature-dependent relaxation time of the free surface region ranges from a few thousand seconds at room temperature to being on the order of seconds at temperatures near the bulk $T_{\mathrm{g}}$. Optical photobleaching studies ${ }^{27}$ have indicated that the thickness of the mobile layer at the region near the free surface increases with temperature. Moreover, the properties at the region near the free surface depend not only on the temperature but also on the heating and cooling rates. For the region near the substrate interface, dewetting experiments ${ }^{28}$ have suggested that film rupture strongly depends on its thermal history, especially the aging time, thus indicating that the relaxation time of supported films is significantly long and has an unusual temperature dependence, even for the relatively weak interactions between the film and the substrate.

${ }^{1}$ Shanghai Institute of Applied Physics, Chinese Academy of Sciences, Shanghai, China and ${ }^{2}$ Department of Physics, School of Science and Technology, Kwansei Gakuin University, Sanda, Japan

Correspondence: Dr C Yang or Professor I Takahashi, Department of Physics, School of Science and Technology, Kwansei Gakuin University, 2-1 Gakuen, Sanda, Hyogo 6691337, Japan.

E-mail: yangchunming@sinap.ac.cn or z96019@kwansei.ac.jp

Received 29 April 2014; revised 17 July 2014; accepted 17 July 2014; published online 10 September 2014 
The $T_{\mathrm{g}} \mathrm{s}$ of thin PS films at various cooling rates have been effectively measured via ellipsometric and calorimetric methods. ${ }^{29,30}$ According to these studies, $T_{\mathrm{g}}$ decreases with decreasing thickness, with the reduction in $T_{\mathrm{g}}$ being significantly higher with decreases in the cooling rate. In our recent study, ${ }^{31}$ we demonstrated a significant reduction in $T_{\mathrm{g}}$ at a relatively slower cooling rate of $0.01{ }^{\circ} \mathrm{C} \mathrm{min}{ }^{-1}$, and the width of the glass transition $w$ was found to decrease with decreases in the cooling rate. These results clearly indicated that unique confinement effects can be notably observed at very low heating and cooling rates or at low frequencies. In the present study, we have investigated the thickness and temperature dependence of $T_{\mathrm{g}}$ and $\alpha_{\text {glass }}$ in supported PS films via X-ray reflectivity (XR) at low heating rates ranging from 0.14 to $0.01{ }^{\circ} \mathrm{C} \mathrm{min}^{-1}$. We have reanalyzed our previously published data ${ }^{32}$ to obtain deeper insights on the thickness and rate dependence of the glass transition temperature of supported PS films and to show a reconstructed novel depth profile of linear expansivity. Our results indicate a slight decrease in $\alpha_{\text {glass }}$ at a heating rate of $0.14^{\circ} \mathrm{Cmin}^{-1}$, whereas we observed a significant increase in $\alpha_{\text {glass }}$ at an ultra-low heating rate of $0.01^{\circ} \mathrm{C} \mathrm{min}^{-1}$. The reconstructed depth profiles of the thermal expansivity obtained by fitting the obtained $\alpha_{\text {glass }}$ values with an integral model indicate a change in the relaxation process over the entire film from the free surface to the substrate interface.

\section{EXPERIMENTAL PROCEDURE}

In this study, atactic PS (Polymer Source Inc., Montreal, QC, Canada) with a molecular weight of $M_{\mathrm{W}}=5.4 \times 10^{4} \mathrm{~g} \mathrm{~mol}^{-1}\left(M_{\mathrm{w}} / M_{\mathrm{n}}=1.04, R_{\mathrm{g}} \sim 6 \mathrm{~nm}\right)$ was used to prepare PS films. In a typical process, a predetermined quantity of PS was dissolved in toluene to form the precursor solution, which was subsequently spin coated onto a Si (100) wafer that was covered with a native silicon dioxide layer. The spin-coating process was performed at a speed of 4000 r.p.m. for $50 \mathrm{~s}$. The thickness of the PS film was controlled by varying the concentration of PS dissolved in toluene $\left(0.11 \times 10^{-2}, 0.16 \times 10^{-2}\right.$, $0.35 \times 10^{-2}, 1.0 \times 10^{-2}$ and $2.0 \times 10^{-2} \mathrm{~g} \mathrm{~mol}^{-1}$ for $4,6,12,25$ and $60 \mathrm{~nm}$ films, respectively). The spin-coated films were annealed in a low vacuum at $127^{\circ} \mathrm{C}\left(T_{\mathrm{g}}(\right.$ bulk $\left.)+27^{\circ} \mathrm{C}\right)$ for $12 \mathrm{~h}$ and subsequently cooled to room temperature over a time period of $4 \mathrm{~h}$. Before XR data acquisition, the surface topography of the films was observed using atomic force microscopy. Later, specular XR measurements were performed using a high-resolution four-circle X-ray diffractometer equipped with a Ge (200) crystal monochromator $\left(0.15406 \mathrm{~nm}\left(\mathrm{CuK} \alpha_{1}\right.\right.$ radiation); SLX2000 + Ultra-X, Rigaku Co., Akishima, Japan). Data were acquired for $25 \mathrm{~min}$ at each isothermal step, and the XR curve was collected under a dry nitrogen atmosphere. The sample temperature was controlled using a homemade heater coupled with a thyristor regulator (SU12AM241-MSNNNN, CHINO, Tokyo, Japan) that was capable of controlling the temperature with an accuracy of $\pm 0.2^{\circ} \mathrm{C}$. Following the $\mathrm{XR}$ measurements at a certain temperature, the sample was heated in $5^{\circ} \mathrm{C}$ increments with a constant heating rate $\left(0.5,0.05\right.$ and $\left.0.01^{\circ} \mathrm{C} \mathrm{min}{ }^{-1}\right)$ from room temperature to $130{ }^{\circ} \mathrm{C}$. Taking into account the $\mathrm{XR}$ data acquisition time and the cooling time, the average (actual) heating rates during the heating process were estimated to be $0.14,0.04$ and $0.01{ }^{\circ} \mathrm{Cmin}^{-1}$, respectively. The XR data were fitted using Parratt formalism by assuming a three-layer model comprising air, a PS layer and a Si substrate. From the XR data, the thickness of the PS film was determined with an accuracy of $0.01 \mathrm{~nm}$. The details of the analysis have been previously described. ${ }^{32,33}$

\section{RESULTS}

Figure 1 illustrates the temperature dependence of the normalized thicknesses that were obtained at heating rates of $0.14^{\circ} \mathrm{C} \mathrm{min}-1$ (open circles), $0.04{ }^{\circ} \mathrm{Cmin}^{-1}$ (open squares) and $0.01^{\circ} \mathrm{C} \mathrm{min}{ }^{-1}$ (open triangles). The initial thickness values measured at room temperature were $\sim 60 \mathrm{~nm}$ (Figure 1a), $24 \mathrm{~nm}$ (Figure $1 \mathrm{~b}$ ), $12 \mathrm{~nm}$ (Figure 1c) and $6 \mathrm{~nm}$ (Figure 1d). The solid curves shown in Figure 1 are the fitted curves obtained by assuming the 'tanh' profile approximation: ${ }^{4}$

$$
h(T)=w\left(\frac{M-G}{2}\right) \ln \left[\cosh \left(\frac{T-T_{g}}{w}\right)\right]+\left(T-T_{\mathrm{g}}\right)\left(\frac{M+G}{2}\right)+c
$$

where $w$ and $c$ represent the width of the glass transition and the thickness at $T=T_{\mathrm{g}}$, respectively. $M$ and $G$ correspond to the curve's slope, extrapolated to the lowest and highest temperatures, respectively, which could be estimated separately by applying a linear fit to the data in both the rubbery and glassy regimes. The values of $M$ and $G$ are regarded as constants in the fitting procedure for obtaining $w, c$ and $T_{\mathrm{g}}$ using Equation (1). The dashed lines in Figure 1 correspond to the linear fits of the slope equal to $M$ or $G$. The intersection of the dashed lines corresponds to $T_{\mathrm{g}}$. As observed in Figure 1a, the $T_{\mathrm{g}}$ value of the 60 -nm-thick PS films was apparently shifted to lower temperatures with decreases in the heating rate (the arrows denote the $T_{\mathrm{g}}$ values). The heating rate dependence of $T_{\mathrm{g}}$ was also confirmed in Figures $1 \mathrm{~b}$ and c. A significant reduction in the $T_{\mathrm{g}}$ value was observed in the 6-nm-thick PS films (Figure 1d), where $T_{\mathrm{g}}$ decreased from $92 \pm 2$ to $60 \pm 2{ }^{\circ} \mathrm{C}$ when the heating rate was decreased from 0.14 to $0.01{ }^{\circ} \mathrm{Cmin}^{-1}$. The values obtained are summarized in Table 1 , and these results clearly indicate that the magnitude of the $T_{\mathrm{g}}$ reduction was notably larger for thinner films compared with thicker films. In addition, the thermal linear expansivity in the rubbery state $\alpha_{\text {rubber }}$ and that in the glassy state $\alpha_{\text {glass }}$, which correspond to the values of $G$ and $M$ in Equation (1), respectively, are also listed in Table 1 . At temperatures above $T_{\mathrm{g}}$, the value of $\alpha_{\text {rubber }}$ appears to be independent of the heating rate for all of the films, with the exception of the film with the lowest thickness of $6 \mathrm{~nm}$. With decreases in film thickness, the value of $\alpha_{\text {rubber }}$ increased, which was consistent with the trend reported in previous studies. ${ }^{20,34}$ At temperatures below $T_{\mathrm{g}}$, the value of $\alpha_{\text {glass }}$ for the 60 -nm-thick film at a heating (an unexpectedly small $\alpha_{\text {glass }}$ is observed at a heating rate of $0.04{ }^{\circ} \mathrm{C} \mathrm{min}^{-1}$ (Figure 1c), which can be considered as an effect of insufficient thermal treatment of this sample) rate of $0.14^{\circ} \mathrm{Cmin}^{-1}$ was determined to be $1.6 \times 10^{-4}{ }^{\circ} \mathrm{C}^{-1}$, which is in good agreement with previously reported values. ${ }^{21,23}$ In the case of thicker films $(\sim 60$ and $24 \mathrm{~nm}$ ), no remarkable increase in the value of $\alpha_{\text {glass }}$ was observed with decreases in the heating rate. This result is again consistent with the $\alpha_{\text {glass }}$ value reported for 70 -nm-thick films of molecular weight $2.34 \times 10^{5} \mathrm{~g} \mathrm{~mol}^{-1}$ measured at heating rates of 0.5 and $0.01{ }^{\circ} \mathrm{Cmin}^{-1} .32$ However, in the case of the thinner films $(\sim 12$ and $6 \mathrm{~nm}$ ), the $\alpha_{\text {glass }}$ value was found to increase with decreases in the heating rate.

\section{DISCUSSION}

Figure 2 illustrates the temperature dependence of the $T_{\mathrm{g}}$ of PS films obtained at various heating rates. The solid curves correspond to the fitted values obtained using the following equation:

$$
T_{\mathrm{g}}(h)=T_{\mathrm{g}}(\infty)\left[1-\left(\frac{A}{h}\right)^{\gamma_{1}}+\left(\frac{B}{h}\right)^{\gamma_{2}}\right]
$$

which can be referred to as a 'three-layer model' developed from the widely accepted empirical expression $T_{\mathrm{g}}(h)=T_{\mathrm{g}}(\infty)\left[1-(A / h)^{\gamma}\right]$ that is conventionally used to describe the $T_{\mathrm{g}}$ reduction in thin polymer films. Here, $T_{\mathrm{g}}(\infty)$ and $T_{\mathrm{g}}(h)$ represent the glass transition temperatures of a bulk and thin film, respectively; $h$ is the film thickness; $A$ and $B$ are the characteristic length scales corresponding to the reduction in $T_{\mathrm{g}}$ depression and the increase in $T_{\mathrm{g}}$, respectively; and $\gamma_{1}$ and $\gamma_{2}$ are dimensionless exponents. The $T_{\mathrm{g}}$ obtained at a heating rate of $0.14{ }^{\circ} \mathrm{Cmin}^{-1}$ appeared to be independent of the film 
a
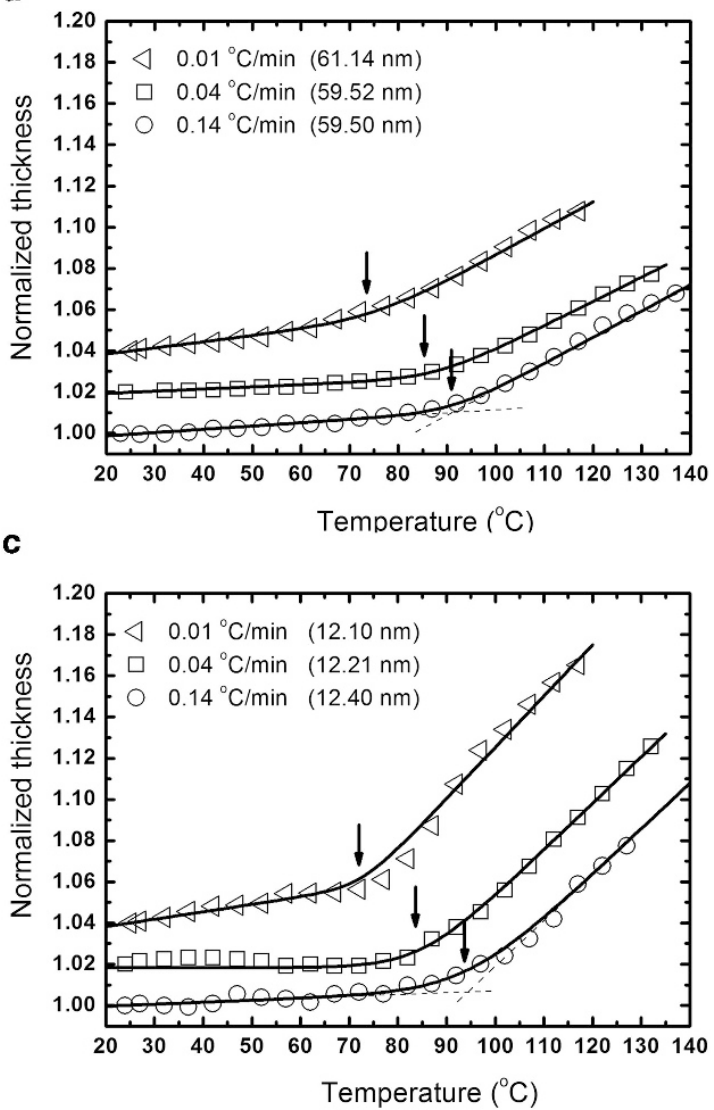

b

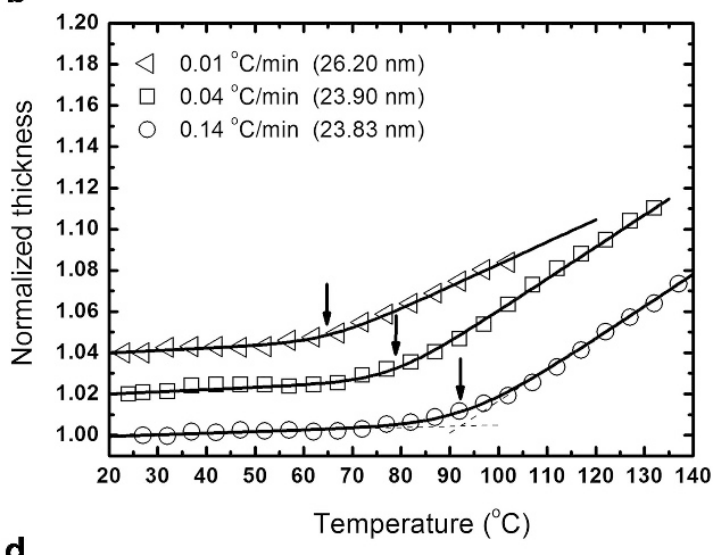

d

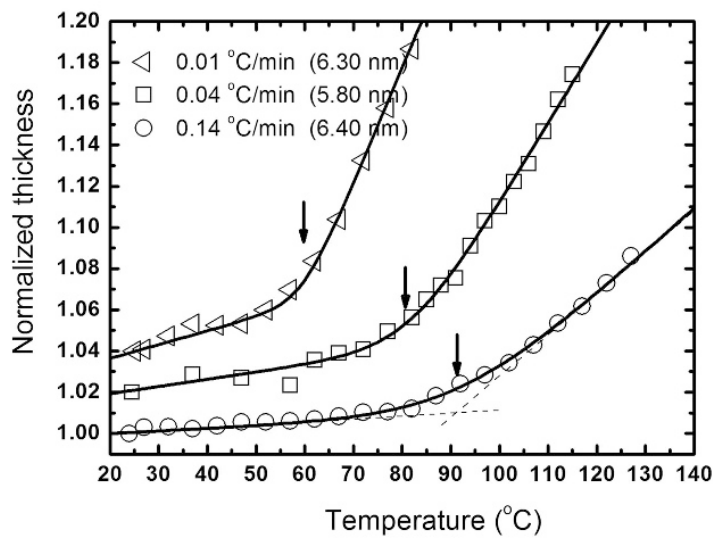

Figure 1 Temperature dependence of the normalized thickness of polystyrene (PS) films $\left(M_{\mathrm{w}}=5.4 \times 10^{4} \mathrm{gmol}^{-1}\right)$ obtained at various heating rates $\left(0.14^{\circ} \mathrm{C} \mathrm{min}-1\right.$ (circles), $0.04{ }^{\circ} \mathrm{C} \mathrm{min}^{-1}$ (squares) and $0.01^{\circ} \mathrm{C} \mathrm{min}-1$ (triangles)). The initial values of the thickness at room temperature were $\sim 60 \mathrm{~nm}$ (a), $24 \mathrm{~nm}$ (b), $12 \mathrm{~nm}$ (c) and $6 \mathrm{~nm}$ (d), as shown within the parentheses. The solid curves correspond to the data fitted using Equation (1). The dashed lines represent a linear fit of the data in the glassy and rubbery states. For clarity, each curve is shifted vertically by 0.02 . Several data published in Yang and Takahashi ${ }^{32}$ were used here to reanalyze the $T_{\mathrm{g}}$ and linear expansivities.

thickness, and the $T_{\mathrm{g}}$ obtained at a heating rate of $0.04{ }^{\circ} \mathrm{C} \mathrm{min}{ }^{-1}$ tended to decrease with decreasing thickness. A significant reduction in $T_{\mathrm{g}}$ was observed at an ultra-low heating rate of $0.01^{\circ} \mathrm{C} \mathrm{min}{ }^{-1}$. From the data measured at a heating rate of $0.14^{\circ} \mathrm{C} \mathrm{min}^{-1}$, the bestfit parameters were obtained as $T_{\mathrm{g}}(\infty)=94.0 \pm 0.5^{\circ} \mathrm{C}, A=0.2 \pm 0.1$ $\mathrm{nm}, \gamma_{1}=1.4 \pm 0.3, B=0.4 \pm 0.3 \mathrm{~nm}$ and $\gamma_{2}=1.8 \pm 0.2$. Upon decreasing the heating rate, the parameter $A$ increased, whereas the parameter $B$ decreased, as indicated in the inset presented in Figure 2. This behavior corresponds to the change in $T_{\mathrm{g}}$ observed under the slow heating processes. The $T_{\mathrm{g}}$ reduction of free-standing films with decreasing thicknesses was much steeper than that of the supported films obtained at rates of 0.14 and $0.04{ }^{\circ} \mathrm{C} \mathrm{min}{ }^{-1}$, suggesting that the molecular chains confined in the substrate region greatly influence the $T_{\mathrm{g}}$ reduction. However, at an ultra-low heating rate, the $T_{\mathrm{g}}$ reduction of the supported films became noticeable, and the $T_{\mathrm{g}} \mathrm{s}$ of supported films with several $\mathrm{nm}$ thicknesses observed at $0.01{ }^{\circ} \mathrm{C} \mathrm{min}^{-1}$ were comparable to the $T_{\mathrm{g}} \mathrm{s}$ of free-standing films with a thickness of $\sim 30 \mathrm{~nm}$.

Figure 3 shows the variations in $\alpha_{\text {glass }}$ obtained at the various heating rates. At a heating rate of $0.04{ }^{\circ} \mathrm{Cmin}^{-1}$, a slightly larger value of $\alpha_{\text {glass }}$ was estimated for the film with the lowest thickness of $6 \mathrm{~nm}$. However, at a heating rate of $0.14^{\circ} \mathrm{C} \mathrm{min}^{-1}$, the value of $\alpha_{\text {glass }}$ slightly decreased with thickness, which is similar to the XR results reported in the literature, ${ }^{23}$ although $\alpha_{\text {glass }}$ exhibited less significant changes in the present results. Furthermore, at an ultra-low heating rate of $0.01{ }^{\circ} \mathrm{C} \mathrm{min}-1$, a significant increase in $\alpha_{\text {glass }}$ was observed, and this trend qualitatively agrees with the ellipsometric measurements previously reported. ${ }^{1,20}$ The dash-dotted curve in Figure 3 corresponds to the data obtained by fitting a two-layer model $\alpha_{\text {glass }}(h)=(\xi / h)\left(\alpha_{\text {rubber }}^{\infty}-\alpha_{\text {glass }}^{\infty}\right)+\alpha_{\text {glass }}^{\infty} 1$ to the data obtained at a heating rate of $0.01{ }^{\circ} \mathrm{Cmin}^{-1}$. The corresponding best-fit parameters were $\alpha_{\text {rubber }}^{\infty}=7.20 \times 10^{-4}{ }^{\circ} \mathrm{C}^{-1}$, $\alpha_{\text {glass }}^{\infty}=1.60 \times 10^{-4}{ }^{\circ} \mathrm{C}^{-1}$ and $\xi=(7.2 \pm 0.4) \mathrm{nm}$, which are consistent with the values reported in Keddie et al. ${ }^{1}$ These results suggest that enhanced mobility in the region near the free surface can be achieved, especially at ultra-low heating rates. The solid curves in Figure 3 correspond to the fitted results obtained using an integral multilayer model: ${ }^{35}$

$$
\langle\alpha(h)\rangle=\frac{\int_{0}^{h} L_{\alpha}(X) w(X) \mathrm{d} X}{\int_{0}^{h} w(X) \mathrm{d} X}=\frac{1}{h} \int_{0}^{h} L_{\alpha}(X) \mathrm{d} X
$$

where $\langle\alpha(h)\rangle$ is the average thermal expansivity value of the film; $L_{\alpha}(X)$ is a profile function of expansivity, which depends on the distance from the solid substrate $X$; and $w(X)$ is the weight function, which was assumed to be unity in this study. For the supported films, 
Table 1 Typical $T_{\mathrm{g}}, \alpha_{\text {glass }}$ and $\alpha_{\text {rubber }}$ values of PS films, obtained from the temperature-thickness profiles measured at different heating rates (several data are cited from Yang and Takahashi ${ }^{32}$ )

\begin{tabular}{lccc}
\hline Heating rate $\left({ }^{\circ} \mathrm{Cmin}^{-1}\right)$ & $\mathrm{T}_{g}\left({ }^{\circ} \mathrm{C}\right)$ & $\alpha_{\text {glass }}\left(\times 10^{-4}{ }^{\circ} \mathrm{C}^{-1}\right)$ & $\alpha_{\text {rubber }}\left(\times 10^{\left.-3{ }^{\circ} \mathrm{C}^{-1}\right)}\right.$ \\
\hline Thickness $~ 60 \mathrm{~nm}$ & & & \\
0.14 & $93 \pm 2$ & $1.6 \pm 0.1$ & $1.2 \pm 0.2$ \\
0.04 & $87 \pm 2$ & $1.0 \pm 0.1$ & $1.2 \pm 0.1$ \\
0.01 & $75 \pm 5$ & $2.9 \pm 0.5$ & $1.3 \pm 0.1$ \\
& & & \\
Thickness $24 \mathrm{~nm}$ & & & \\
0.14 & $93 \pm 2$ & $0.8 \pm 0.2$ & $1.5 \pm 0.2$ \\
0.04 & $79 \pm 3$ & $1.1 \pm 0.3$ & $1.5 \pm 0.1$ \\
0.01 & $65 \pm 2$ & $1.1 \pm 0.3$ & $1.1 \pm 0.1$ \\
& & & \\
Thickness $\sim 12 \mathrm{~nm}$ & & & \\
0.14 & $94 \pm 2$ & $1.0 \pm 0.3$ & $2.2 \pm 0.2$ \\
0.04 & $85 \pm 2$ & $0.1 \pm 0.1$ & $2.0 \pm 0.2$ \\
0.01 & $74 \pm 5$ & $3.6 \pm 0.5$ & $2.0 \pm 0.1$ \\
& & & \\
Thickness $\sim 6 \mathrm{~nm}$ & & & $1.9 \pm 0.2$ \\
0.14 & $92 \pm 2$ & $1.2 \pm 0.2$ & $3.9 \pm 0.1$ \\
0.04 & $82 \pm 2$ & $3.4 \pm 0.2$ & $5.6 \pm 0.5$ \\
0.01 & $60 \pm 2$ & $6.7 \pm 0.9$ &
\end{tabular}

Abbreviations: $\alpha_{\text {glass }}$, linear expansivity in glassy state; PS, polystyrene; $\alpha_{\text {rubben }}$ linear expansivity in rubbery state; $T_{\mathrm{g}}$, glass transition temperature.

The corresponding data in Figure 2 are indicated by closed symbols.

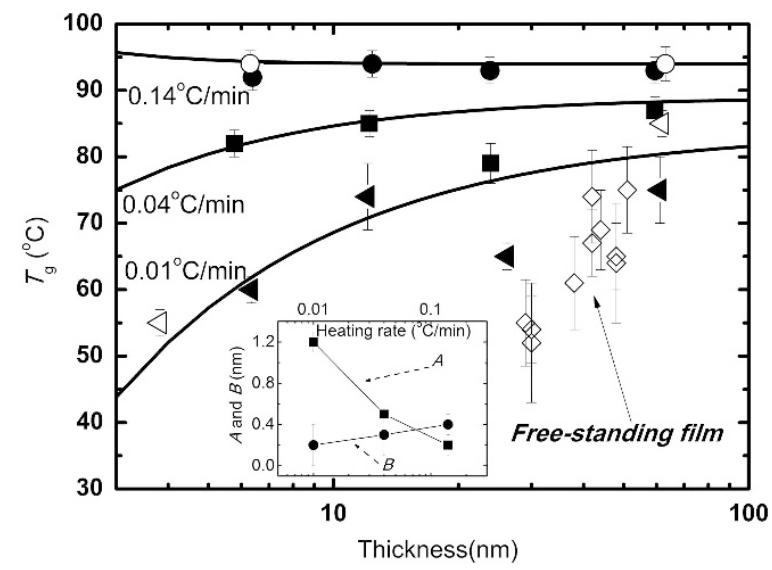

Figure 2 Thickness dependence of the $T_{\mathrm{g}}$ of supported films $\left(M_{w}=54000 \mathrm{~g} \mathrm{~mol}^{-1}\right)$ obtained at various heating rates $\left(0.14{ }^{\circ} \mathrm{C} \mathrm{min}^{-1}\right.$ (circles), $0.04^{\circ} \mathrm{C} \mathrm{min}^{-1}$ (squares) and $0.01^{\circ} \mathrm{C} \mathrm{min}^{-1}$ (triangles)). The curves were fitted using Equation (2). The rhombuses show the $T_{\mathrm{g}} \mathrm{S}$ of freestanding films $\left(M_{\mathrm{w}}=303000 \mathrm{~g} \mathrm{~mol}^{-1}\right)$ obtained at a conventional heating rate (cited from Miyazaki et al. ${ }^{25}$ ). The inset shows the heating-rate dependence of the fitting parameters $A$ (full squares) and $B$ (full circles), defined in Equation (2). The error bars represent the standard deviation of $T_{\mathrm{g}}$, evaluated from the linear fits (at the points indicated by arrows in Figure 1).

$L_{\alpha}(X)$ in the glassy state can be defined as ${ }^{35}$

$$
L_{\alpha}(X)_{\text {glass }}=\left\{\begin{array}{lc}
0 & 0 \leq X \leq \delta_{\mathrm{I}} \\
\alpha_{\text {glass }}^{\infty}\left(1+\frac{\lambda_{I}^{2}}{X^{2}}\right)+\alpha_{\text {rubber }}^{\infty} \frac{\lambda_{\mathrm{S}}^{2}}{(h-X)^{2}} & \delta_{\mathrm{I}}<X<h-\delta_{\mathrm{S}} \\
\alpha_{\text {rubber }}^{\infty} & h-\delta_{\mathrm{S}} \leq X \leq h
\end{array}\right.
$$

where $\alpha_{\text {glass }}^{\infty}=1.60 \times 10^{-4}{ }^{\circ} \mathrm{C}^{-1}$ and $\alpha_{\text {rubber }}^{\infty}=7.20 \times 10^{-4}{ }^{\circ} \mathrm{C}^{-1}$ are the fixed expansivities of the glassy and rubbery states of bulk PS,

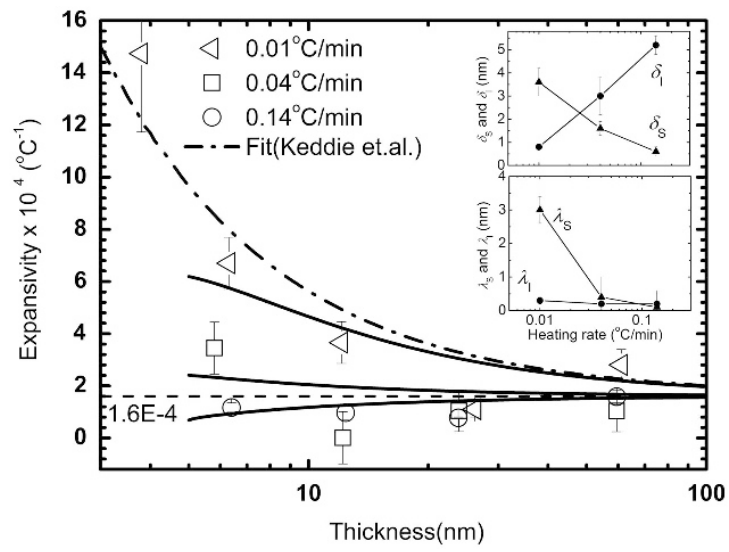

Figure 3 The $\alpha_{\text {glass }}$ values of the polystyrene (PS) films measured at heating rates of $0.14{ }^{\circ} \mathrm{C} \mathrm{min}^{-1}$ (circles), $0.04{ }^{\circ} \mathrm{C} \mathrm{min}^{-1}$ (squares) and $0.01{ }^{\circ} \mathrm{C} \mathrm{min}-1$ (triangles) and plotted as a function of the film thickness. The solid curves were fitted using Equation (5), and the dash-dotted curve corresponds to a fit using the two-layer model described in the text. The insets illustrate the fitted $\delta s$ and $\lambda$ s values plotted as a function of the heating rate.

respectively. Both of these values are consistent with the values reported in the literature. ${ }^{19,21}$

In the equation above, the parameter $\delta_{\mathrm{I}}$ represents a characteristic length scale in the immobilization region near the solid substrate, where the polymer segments are pinned onto the substrate to form a dead layer that is characterized by severely reduced thermal expansivity. With an increase in $X$, the pinning effect decreases, and the polymer chains consequently exhibit properties similar to those observed in bulk polymers. In addition, the parameter $\lambda_{\mathrm{I}}$ represents a characteristic length scale that indicates the region devoid of the pinning effect. ${ }^{35}$ The parameter $\delta_{\mathrm{S}}$ represents the thickness of the region with enhanced mobility near the free surface that has a thermal expansivity of $\alpha_{\text {rubber }}^{\infty}$. The parameter $\lambda_{\mathrm{S}}$ reflects a perturbation length scale, within which the enhanced mobility can propagate into the interior of the PS film. In this model, the buried interfacial region of thickness $\delta_{\mathrm{I}}$ is responsible for the decrease in expansivity. The average value of thermal expansivity in the glassy state of thin films with a thickness of $h>\left(\delta_{\mathrm{I}}+\delta_{\mathrm{S}}\right),\left(<\alpha(h)>_{\text {glass }}\right)$ is readily obtained from Equations (3) and (4) as follows:

$$
\begin{aligned}
\langle\alpha(h)\rangle_{\text {glass }}= & \frac{1}{h}\left[\alpha_{\text {glass }}^{\infty}\left(h-\delta_{\mathrm{I}}-\delta_{\mathrm{S}}\right)+\alpha_{\text {glass }}^{\infty} \lambda_{\mathrm{I}}^{2}\left(\frac{1}{\delta_{\mathrm{I}}}-\frac{1}{h-\delta_{\mathrm{S}}}\right)\right. \\
& \left.+\alpha_{\text {rubber }}^{\infty} \lambda_{\mathrm{S}}^{2}\left(\frac{1}{\delta_{\mathrm{S}}}-\frac{1}{h-\delta_{\mathrm{I}}}\right)+\alpha_{\text {rubber }}^{\infty} \delta_{\mathrm{S}}\right]
\end{aligned}
$$

The insets in Figure 3 show the fitted values of $\delta_{\mathrm{s}}$ and $\lambda_{\mathrm{s}}$. As shown in the upper inset, a decrease in the heating rate resulted in a decrease in $\delta_{\mathrm{I}}$ (full circles) and an increase in $\delta_{\mathrm{S}}$ (full triangles). In contrast, as shown in the lower inset, a decrease in the heating rate resulted in a slight increase in $\lambda_{\mathrm{I}}$ (full circles) and a significant increase in $\lambda_{\mathrm{S}}$ (full triangles). All of the fitted parameters are listed in Table 2. The heating rates can be correlated with relaxation times by assuming from posteriori knowledge that a rate of temperature variation of $10^{\circ} \mathrm{C} \mathrm{min}^{-1}$ corresponds to a relaxation time of $\sim 100 \mathrm{~s}$ for polymers in the glassy state. ${ }^{29,36}$ In Figure 4, the heating rates have been directly converted to the relaxation time using this relationship, and the $\delta_{S} \mathrm{~s}$ values (solid squares) represent the thickness of the mobile surface layer. The triangles and circles in Figure 4 correspond to the thickness of the surface layer at a temperature near the bulk $T_{\mathrm{g}}$ (triangles: $94{ }^{\circ} \mathrm{C}$ ) 
Table 2 Parameters $\delta$ and $\lambda$ obtained by an integral model fit of the $\alpha_{\text {glass }}$ of the PS films measured at various heating rates

\begin{tabular}{lcccc}
\hline Rate $\left({ }^{\circ} \mathrm{Cmin}^{-1}\right)$ & $\delta_{l}(\mathrm{~nm})$ & $\lambda_{I}(\mathrm{~nm})$ & $\delta_{S}(\mathrm{~nm})$ & $\lambda_{S}(\mathrm{~nm})$ \\
\hline 0.14 & $5.2 \pm 0.4$ & $0.2 \pm 0.2$ & $0.6 \pm 0.2$ & $0.1 \pm 0.1$ \\
0.04 & $3.0 \pm 0.8$ & $0.2 \pm 0.2$ & $1.6 \pm 0.3$ & $0.4 \pm 0.2$ \\
0.01 & $0.8 \pm 0.3$ & $0.3 \pm 0.3$ & $3.6 \pm 0.6$ & $3.0 \pm 0.4$ \\
\hline
\end{tabular}

Abbreviations: $\alpha_{\text {glass }}$, linear expansivity in glassy state; PS, polystyrene.

The definitions of $\delta_{1}, \lambda_{1}, \delta_{\mathrm{S}}$ and $\lambda_{\mathrm{S}}$ are shown in Equation (4).

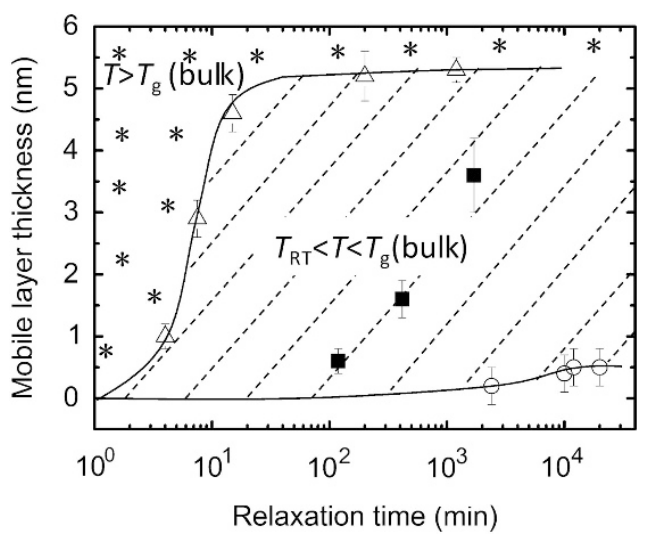

Figure 4 Plot illustrating the average thickness of the mobile layer near the free surface of the polystyrene (PS) film as a function of the relaxation time. The data corresponding to the temperature near $T_{\mathrm{g}}$ (bulk) (triangles) and that corresponding to room temperature (circles) with the fitted curves (solid lines) are cited from Qi et al. ${ }^{26}$ The $\delta_{S}$ S values shown by solid squares were estimated by directly converting the heating rate to relaxation time. The relationship between heating rate and relaxation time has been elaborated in the text.

and at room temperature (circles: $26^{\circ} \mathrm{C}$ ), which was estimated by embedding gold nanoparticles into the free surface of PS. ${ }^{26}$ When the temperature lies between $T_{\mathrm{RT}}$ and $T_{\mathrm{g}}$ (bulk), any data for the mobile surface layer thickness that is labeled according to the relaxation time should lie in the region between the solid curves (the hatched region indicates $T_{\mathrm{RT}}<T<T_{\mathrm{g}}$ (bulk)). Because the temperature is between $T_{\mathrm{RT}}$ and $T_{\mathrm{g}}$ (bulk), the heating rate-dependent $\delta_{\mathrm{S}}$ values obtained in this study (solid squares in Figure 4) are quite reasonable. Moreover, the $\delta_{S}$ s values are also consistent with previously reported values, ${ }^{27}$ in which the thicknesses of the surface layer were calculated to range from 0 to $4 \mathrm{~nm}$ when the temperature increased from 47 to $94{ }^{\circ} \mathrm{C}$. Figure 5 illustrates the reconstructed profiles of $L_{\alpha}(X)_{\text {glass }}$ that were calculated from the fitted parameters. These data provide deeper insight into the thermal expansivities in PS films with thicknesses comparable to the end-to-end average distance of the molecular chains. At a heating rate of $0.14{ }^{\circ} \mathrm{C} \mathrm{min}^{-1}$ (Figure 5a), we observed a 5 -nm-thick dead layer with zero expansion near the substrate $(0<X<5 \mathrm{~nm})$ and an ultrathin region near the free surface with the most enhanced expansivity $(11.5 \mathrm{~nm}<X<12 \mathrm{~nm})$. Between them, there exists a 6-nm-thick region that has the same expansivity as the bulk PS. When the heating rate was decreased (Figure 5b), the thickness of the interfacial dead layer $(0 \mathrm{~nm}<X<3 \mathrm{~nm})$ decreased, whereas that of the free surface region $(10.5 \mathrm{~nm}<X<12 \mathrm{~nm})$ increased. At an ultra-low heating rate of $0.01{ }^{\circ} \mathrm{C} \mathrm{min}^{-1}$ (Figure 5c), the reconstructed thermal expansivity profile continuously decreased with decreases in $X$, in contrast to the step-like profile shown in Figure 5a. The trend observed in the

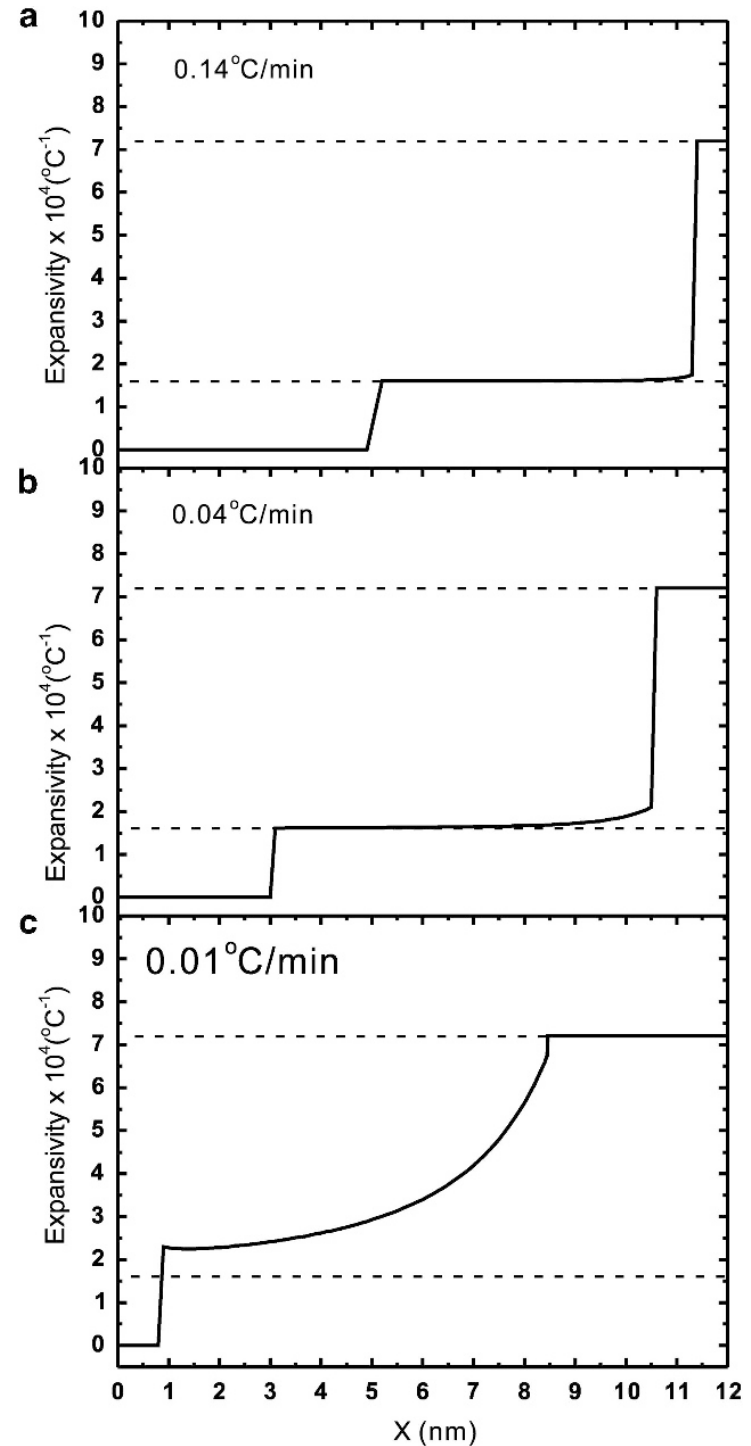

Figure 5 Reconstructed depth profiles of the thermal expansivity of the polystyrene (PS) films in the glassy state with a thickness of $\sim 12 \mathrm{~nm}$ $\left(\sim 2 R_{\mathrm{g}}\right)$ obtained at heating rates of $0.14^{\circ} \mathrm{C} \mathrm{min}^{-1}$ (a), $0.04{ }^{\circ} \mathrm{C} \mathrm{min}^{-1}$ (b) and $0.01^{\circ} \mathrm{C} \mathrm{min}^{-1}$ (c).

reconstructed thermal expansivity profiles, which were obtained using the multilayer model, strongly suggests that the polymer segments in the region near the substrate can relax under the ultralow temperature variations. Furthermore, it suggests that the effects of enhanced mobility in the region adjacent to the free surface are only observable on very long time scales, which leads to an increase in the average thermal expansivity as well as a reduction in the $T_{\mathrm{g}}$ value of the film.

The negligible thickness dependence of $T_{\mathrm{g}}$ at a heating rate of $0.14{ }^{\circ} \mathrm{C} \mathrm{min}{ }^{-1}$ is consistent with previously reported results, ${ }^{15}$ as there was no reduction in the $T_{\mathrm{g}}$ value of PS at a conventional temperature variation rate $\left(2{ }^{\circ} \mathrm{C} \mathrm{min}^{-1}\right)$ with decreases in the thickness to $10 \mathrm{~nm}$. To analyze this result, the following two modes of relaxation were considered: (1) a segmental mode resulting from the configurational translations of a few monomer segments and (2) a normal mode associated with fluctuations in the end-to-end distance of the molecular chains. ${ }^{15}$ The negligible thickness dependence of $T_{\mathrm{g}}$ can 
be attributed to the weak, short length-scale free surface effect on cooperative motion, ${ }^{15,37}$ which can be verified from the step-like profile with small $\delta_{\mathrm{S}}$ seen in Figure $5 \mathrm{a}$. Nonetheless, several studies, including those associated with free-standing films showing reductions in $T_{\mathrm{g}}$ around a heating rate of $0.5^{\circ} \mathrm{C} \mathrm{min}{ }^{-1}, 4,25,38$ contradict the result at $0.14^{\circ} \mathrm{C} \mathrm{min}^{-1}$ that was obtained in the present study. One reason for this discrepancy may be the stepwise variation in temperature when the samples were held isothermally for some time for the XR data acquisition $(\sim 20 \mathrm{~min})$ and then subjected to continuous temperature variation at a constant rate to reach the target temperature. However, the trend of a large reduction in $T_{\mathrm{g}}$ at slower rates qualitatively agrees with several ellipsometric measurements. 1,20

The characteristics of polymer chains at interfaces strongly depend on their thermal history. During the spin coating process, polymer segments might have established intimate contact with the substrate, and consequently they may have tended to deviate from the natural configuration of the molecular chains. Furthermore, the postannealing treatment under vacuum eliminates residual solvent, thereby leading to a more relaxed configuration in the sample. However, realizing a fully relaxed configuration is almost practically impossible, especially at the deeply buried interface. Furthermore, the dewetting experiments performed by Reiter et al. ${ }^{28}$ indicated the presence of persistent residual stress in the region near the substrate interface, where the relaxation time was significantly longer. Remarkably lower heating or cooling rates might encourage the molecular chains in the interfacial region to form more relaxed configurations that typically require longer time. The reconstructed thermal expansivity profiles presented in Figure 5 support this perspective. At lower heating rates, a slow relaxation peculiar to the bulk glass-like region gradually proceeds toward the solid substrate. This process causes a decrease in the dead-layer region, which is characterized by zero- $\alpha_{\text {glass }}$, while also increasing the thickness of the mobile layer at the free surface. The explanation for the observed reduction in $T_{\mathrm{g}}$ at the lower heating rates of 0.04 and $0.01{ }^{\circ} \mathrm{C} \mathrm{min}^{-1}$, shown in Figure 3, can thus be twofoldnamely, the decrease in $\delta_{\mathrm{I}}$ and the increase in $\delta_{\mathrm{S}}$. As evident from Figure $5 \mathrm{a}$, the aforementioned effects would not cause a reduction in $T_{\mathrm{g}}$ at the rate of $0.14^{\circ} \mathrm{C} \mathrm{min}^{-1}$.

\section{CONCLUSIONS}

We have performed long-time measurements to evaluate the glass transition of PS thin films supported on Si substrates at various heating rates using XR. At a heating rate of $0.14^{\circ} \mathrm{C} \mathrm{min}^{-1}$, the glass transition temperature $T_{\mathrm{g}}$ was found to be independent of the film thickness down to a thickness of $6 \mathrm{~nm}$. However, at a lower heating rate of $0.04^{\circ} \mathrm{C} \mathrm{min}^{-1}$ and an ultra-low heating rate of $0.01{ }^{\circ} \mathrm{C} \mathrm{min}{ }^{-1}$, $T_{\mathrm{g}}$ was found to decrease with decreasing thickness. Furthermore, with decreasing thickness, the linear thermal expansivity of the glassy state $\alpha_{\text {glass }}$ decreased slightly at a heating rate of $0.14{ }^{\circ} \mathrm{Cmin}^{-1}$, whereas it increased at the lower heating rates of 0.04 and $0.01{ }^{\circ} \mathrm{C} \mathrm{min}{ }^{-1}$. Moreover, reconstructed depth profiles of thermal expansivity were obtained by fitting the obtained $\alpha_{\text {glass }}$ values to an integral model. The reconstructed depth profiles indicated that the length scale of the interfacial dead region decreases with decreases in the heating rate, whereas the thickness of the mobile surface layer increases. These results directly explain the confinement effect that is observed only at low heating rates for supported polymer thin films.

\section{ACKNOWLEDGEMENTS}

This study was financially supported by the Japan Society for the Promotion of Science (Grant-in-Aid for Scientific Research(C) 24560033).
1 Keddie, J. L., Jones, R. A. L. \& Cory, R. A. Size-dependent depression of the glass transition temperature in polymer films. Eur. Phys. Lett. 27, 59 (1994).

2 Paeng, K., Swallen, S. F. \& Ediger, M. D. Direct measurement of molecular motion in freestanding polystyrene thin films. J. Am. Chem. Soc. 133, 8444-8447 (2011).

3 Paeng, K., Richert, R. \& Ediger, M. D. Molecular mobility in supported thin films of polystyrene, poly(methyl methacrylate), and poly(2-vinyl pyridine) probed by dye reorientation. Soft Matter 8, 819-826 (2012).

4 Dalnoki-Veress, K., Forrest, J. A., Murray, C., Gigault, C. \& Dutcher, J. R. Molecular weight dependence of reductions in the glass transition temperature of thin, freely standing polymer films. Phys. Rev. E 63, 031801 (2001).

5 Ellison, C. J. \& Torkelson, J. M. The distribution of glass-transition temperatures in nanoscopically confined glass formers. Nat. Mater. 2, 695 (2003).

6 Inoue, R. Kanaya, T., Nishida, K., Tsukushi, I., Telling, M. T. F., Gabrys, B. J. Tyagi, M., Soles, C. \& Wu, W.-L. Glass transition and molecular mobility in polymer thin films. Phys. Rev. E 80, 031802 (2009).

7 Tanaka, K., Tateishi, Y., Okada, Y., Nagamura, T., Doi, M. \& Morita, H. Interfacial mobility of polymers on inorganic solids. J. Phys. Chem. B 113, 4571-4577 (2009).

8 Inoue, R., Nakamura, M., Matsui, K., Kanaya, T., Nishida, K. \& Hino, M. Distribution of glass transition temperature in multilayered poly (methyl methacrylate) thin film supported on a Si substrate as studied by neutron reflectivity. Phys. Rev. E 88, 032601 (2013).

9 Zhang, C., Fujii, Y. \& Tanaka, K. Effect of long range interactions on the glass transition temperature of thin polystyrene films. ACS Macro Lett. 1, 1317 (2012).

10 Zheng, X., Rafailovich, M. H., Sokolov, J., Strzhemechny, Y., Schwarz, S. A., Sauer, B. B. \& Rubinstein, M. Long-range effects on polymer diffusion induced by a bounding interface. Phys. Rev. Lett. 79, 241 (1997).

11 Forrest, J. A. \& Dalnoki-Veress, K. The glass transition in thin polymer films. Adv Colloid Interface Sci. 94, 167 (2001).

12 Alcoutlabi, M. \& McKenna, G. B. Effect of confinement on material behavior at the nanometre size scale. J. Phys. Condens. Matter 17, R461 (2005).

13 Serghei, A., Huth, H., Schick, C. \& Kremer, F. Glassy dynamics in thin polymer layers having a free upper interface. Macromolecules 41, 3636-3639 (2008).

14 Erber, M., Tress, M., Mapesa, E., Serghei, A., Eichhorn, K.-J., Voit, B. \& Kremer, F. Glassy dynamics and glass transition in thin polymer layers of PMMA deposited on different substrates. Macromolecules 43, 7729-7738 (2010).

15 Tress, M., Erber, M., Mapesa, E. U., Huth, H., Muller, J., Serghei, A., Schick, C. Eichhorn, K.-J., Voit, B. \& Kremer, F. Glassy dynamics and glass transition in nanometric thin layers of polystyrene. Macromolecules 43, 9937-9944 (2010).

16 Ge, S., Pu, Y., Zhang, W., Rafailovich, M., Sokolov, J., Buenviaje, C., Buckmaster, R. \& Overney, R. M. Shear modulation force microscopy study of near surface glass transition temperatures. Phys. Rev. Lett. 85, 2340 (2000).

17 Efremov, M. Y., Olson, E. A., Zhang, M., Zhang, Z. \& Allen, L. H. Glass transition in ultrathin polymer films: calorimetric study. Phys. Rev. Lett. 91, 085703 (2003).

18 Sharp, J. S. \& Forrest, J. A. Dielectric and ellipsometric studies of the dynamics in thin films of isotactic poly(methylmethacrylate) with one free surface. Phys. Rev. E 67, 031805 (2003)

19 Kawana, S. \& Jones, R. A. L. Character of the glass transition in thin supported polymer films. Phys. Rev. E 63, 021501 (2001).

20 Singh, L., Ludovice, P. J. \& Henderson, C. L. Influence of molecular weight and film thickness on the glass transition temperature and coefficient of thermal expansion of supported ultrathin polymer films. Thin Solid Films 449, 231-241 (2004).

21 Kim, S., Hewlett, S. A., Roth, C. B. \& Torkelson, J. M. Confinement effects on glass transition temperature, transition breadth, and expansivity: comparison of ellipsometry and fluorescence measurements on polystyrene films. Eur. Phys. J. E 30, 83 (2009).

22 DeMaggio, G. B., Frieze, W. E., Gidley, D. W., Zhu, M., Hristov, H. A. \& Yee, A. F. Interface and surface effects on the glass transition in thin polystyrene films. Phys. Rev. Lett. 78, 1524 (1997).

23 Miyazaki, T., Nishida, K. \& Kanaya, T. Thermal expansion behavior of ultrathin polymer films supported on silicon substrate. Phys. Rev. E 69, 061803 (2004).

24 Soles, C. L., Douglas, J. F., Wu, W., Peng, H. \& Gidley, D. W. Comparative specular X-ray reflectivity, positron annihilation lifetime spectroscopy, and incoherent neutron scattering measurements of the dynamics in thin polycarbonate films. Macromolecules 37, 2890-2900 (2004)

25 Miyazaki, T., Inoue, R., Nishida, K. \& Kanaya, T. X-ray reflectivity studies on glass transition of free standing polystyrene thin films. Eur. Phys. J. Special Top. 141, 203-206 (2007)

26 Qi, D., Ilton, M. \& Forrest, J. A. Measuring surface and bulk relaxation in glassy polymers. Eur. Phys. J. E 34, 56 (2011).

27 Paeng, K., Swallen, S. F. \& Ediger, M. D. J. Direct measurement of molecular motion in freestanding polystyrene thin films. J. Am. Chem. Soc. 133, 8444-8447 (2011).

28 Reiter, G., Hamieh, M., Damman, P., Sclavons, S., Gabriele, S., Vilmin, T. \& Raphäel, E. Residual stresses in thin polymer films cause rupture and dominate early stages of dewetting. Nat. Mater. 4, 754 (2005).

29 Fakhraai, Z. \& Forrest, J. A. Probing slow dynamics in supported thin polymer films Phys. Rev. Lett. 95, 025701 (2005).

30 Gao, S., Koh, Y. P. \& Simon, S. L. Calorimetric glass transition of single polystyrene ultrathin films. Macromolecules 46, 562-570 (2013).

31 Yang, C., Onitsuka, R. \& Takahashi, I. Confinement effects on glass transition temperature, transition breadth, and linear expansivity: an ultraslow X-ray reflectivity study on supported ultrathin polystyrene films. Eur. Phys. J. E 36, 66 (2013).

32 Yang, C. \& Takahashi, I. Broadening, no broadening and narrowing of glass transition of supported polystyrene ultrathin films emerging under ultraslow temperature variations. Polym. J. 43, 390-397 (2011) 
33 Yang, C., Kitahara, A. \& Takahashi, I. Thickness anomalies in supported polystyrene films with thicknesses comparable to the radius of gyration. Polym. J. 41, 1036-1040 (2009).

34 Bhattacharya, M., Sanyal, M. K., Geue, T. h. \& Pietsch, U. Glass transition in ultrathin polymer films: a thermal expansion study. Phys. Rev. E 71, 041801 (2005).

35 Napolitano, S., Pilleri, A., Rolla, P. \& Wübbenhorst, M. Unusual deviations from bulk behavior in ultrathin films of poly(tert-butylstyrene): can dead layers induce a reduction of Tg? ACS Nano 4, 841 (2010).
36 Roland, C. M. \& Casalini, R. Temperature dependence of local segmental motion in polystyrene and its variation with molecular weight. J. Chem. Phys. 119, 1838 (2003).

37 Bahar, I., Erman, B., Kremer, F. \& Fischer, E. Configuration of a thermotropic polyester from small-angle neutron scattering. Macromolecules 25, 826-831 (1992).

$38 \mathrm{Kim}, \mathrm{S}$. \& Torkelson, J. M. Distribution of glass transition temperatures in freestanding, nanoconfined polystyrene films: a test of de gennes' sliding motion mechanism. Macromolecules 44, 4546-4553 (2011). 